\title{
Single Phase Induction Motor Drive with Restrained Speed and Torque Ripples Using Neural Network Predictive Controller
}

\author{
S. Saravanan ${ }^{1}$, K. Geetha ${ }^{2}$ \\ ${ }^{1}$ Department of Electrical and Electronics Engineering, Sri Sai Ram Institute of Technology, Chennai, India \\ ${ }^{2}$ Department of Electrical and Electronics Engineering, Karpagam Institute of Technology, Coimbatore, India \\ Email: *saratpt_76@yahoo.com, geetha.arulmani@gmail.com
}

How to cite this paper: Saravanan, S. and Geetha, K. (2016) Single Phase Induction Motor Drive with Restrained Speed and Torque Ripples Using Neural Network Predictive Controller. Circuits and Systems, 7, 3670-3684.

http://dx.doi.org/10.4236/cs.2016.711309

Received: May 12, 2016

Accepted: May 30, 2016

Published: September 13, 2016

Copyright (c) 2016 by authors and Scientific Research Publishing Inc. This work is licensed under the Creative Commons Attribution International License (CC BY 4.0).

http://creativecommons.org/licenses/by/4.0/ (c) (i) Open Access

\begin{abstract}
In industrial drives, electric motors are extensively utilized to impart motion control and induction motors are the most familiar drive at present due to its extensive performance characteristic similar with that of DC drives. Precise control of drives is the main attribute in industries to optimize the performance and to increase its production rate. In motion control, the major considerations are the torque and speed ripples. Design of controllers has become increasingly complex to such systems for better management of energy and raw materials to attain optimal performance. Meager parameter appraisal results are unsuitable, leading to unstable operation. The rapid intensification of digital computer revolutionizes to practice precise control and allows implementation of advanced control strategy to extremely multifaceted systems. To solve complex control problems, model predictive control is an authoritative scheme, which exploits an explicit model of the process to be controlled. This paper presents a predictive control strategy by a neural network predictive controller based single phase induction motor drive to minimize the speed and torque ripples. The proposed method exhibits better performance than the conventional controller and validity of the proposed method is verified by the simulation results using MATLAB software.
\end{abstract}

\section{Keywords}

Dynamic Model, Low Torque Ripples, Neural Model, Neural Network Predictive Controller, Unstable Operation, Single Phase Induction Motor, Variable Speed Drives

\section{Introduction}

In recent years, automatic controls are indispensable to the process industries in order 
to minimize complexity of plants control, to maximize the production rate and to meet sharper specification of product quality [1]-[3]. This stipulates the continuous monitoring and control of Industrial Drives (ID) for set point tracking as well as for disturbance rejection [4]-[6]. Suppressing the influence of external disturbances is the most common objective and it is requisite to originate a complex control mechanism that will make the proper changes on the drive to cancel the negative impact, resulting in stable operation of the process with fast response [7] [8]. Nonlinear behavior is very common in nature of almost all the industrial processes; design of stabilizing controller is always preferred to optimize the production [1]. But mathematical modeling of such systems is tremendously exigent due to the association of higher order system equations, which makes additional complication in control parameter evaluation, design and implementation of suitable controller [5]-[7] [9]. Besides most of the controller tuning methods requiring accurate mathematical model of the system to be controlled either in first order with dead time or in the second order form, to accomplish any of this to higher order systems, superior computation skills and time devastating are entailed [2] [10]-[12].

Conventional control is still being used due to its simple structure, high consistency and works well for linear processes with small change in process parameters [2]. But, if the process has a strong interference and ambiguity with a high degree of nonlinearity, only relying on normal Proportional Integral (PI) control is not effective; the use of Neural Network (NN) based controller is the viable alternative, and Model Predictive Control (MPC) is a promising substitute, in the modern era to such composite systems [6] [7] [9] [11]-[15]. Furthermore the high flexibility, powerful and fast acting microprocessors consent to implement such more complex control schemes with fast dynamics [14].

The main concept of the MPC is based on the calculation of the future system behavior to compute optimal manipulated variables. The control variable is the converter output voltage, in the form of a continuous duty cycle. Several MPC methods are used in real time applications [13]-[15]. In this work, Neural Network Predictive Controller (NNPC) based speed controller is designed to a Single Phase Induction Motor (SPIM) and is compared with PI controller. The MATLAB simulation results validate that the proposed NNPC performs better than the conventional PI controller.

\section{Conventional Controllers}

The controllers such as hysteresis based current controllers [1], PSO based controllers [2] [3], genetic algorithm based controllers [9], flux controllers [12], predictive torque controllers [5] [14] and other complex control structures are implemented for induction motors (IM). However, most of the concepts which have been presented in the said literature focus either on current or torque or flux control, which still requires cascade structure. Nevertheless these structures require a rushed acting controller in the inner loop compared to its outer loop, which makes dependency and entail speed to torque or current converters [16]. Torque or flux limiter makes complexity in the control structure. These limitations have been overcome by direct speed control approaches [14] [16]. 


\subsection{Vector Controlled Schemes}

As SPIM comprise unsymmetrical windings, consequences unbalanced impedances, which lead unequal currents. Since the vector control strategies are based on a balanced drive system involving symmetrical motors, it is difficult to fix the phase difference between windings current of 90 degree in SPIM and may require complex implementation to eliminate the unbalanced operation [17]. Modified stator voltage equations are used to compensate its unbalanced operations and implementation of vector control to unbalanced SPIM drive is more complex than for symmetrical motor. Vector controlled two phase induction motor (TPIM) has been recommended as an alternative to SPIM, but still it requires complex coordinate transformations and expressions [17] [18]. Further, TPIM require converters and inverters to employ it with single phase supply.

The essential parameters to the implement of vector-control have been measured precisely and obtained on the conduct of no-load and blocked-rotor tests to the symmetrical machines. Were as in unsymmetrical machines, they produce negative and positive torque during their operation, which makes complication in parameter estimation and leads unbalanced operation [17] [18].

\subsection{Limitations of Direct Torque Control}

Hysteresis controllers with PWM generation increases the complexity, transformations are required to get the $a b c$ frame optimum reference current which complicate the control algorithm and cannot controls the torque directly to get fast torque response [1]. Further they are not prompt like conventional controllers, because it can easily regulate the speed of varying references of torque and flux. DTC switching table fails to consider the circuit limitations, such as neutral-point-balance and smooth vector switching caused by the topology of three-level inverters [19]. Drive performance remains relatively low due to the increase of CPU time, which is linked to the complex vector selection table, low dynamic and higher torque ripple with variable switching frequency [7] [20].

Selection of the inverter states entails the position information of stator flux linkage and direct axis ( $d$-axis) to define the required sector. Correct inverter states selection are essential, that should be used based on the stator flux and torque errors which requires high computational time and composite control logic [12] [21].

\section{Single Phase Induction Motor Model}

Due to outstanding technical developments in control areas and its control simplicity than mechanical drives IM are extensively utilized in range from fractional to few kilo Watts [11]. Tremendous growth in power electronics let it to achieve optimum response with reduced energy in cost-effective method.

Figure 1 illustrates the circuit diagram for speed control of proposed SPIM [14]. The dynamic model of a SPIM using stationary reference frame on neglecting the iron loss and core saturation are given as below [17].

$$
u_{d s}=i_{d s} r_{d s}+\rho\left(i_{d s} L_{d s}+i_{d r} L_{d m}\right)
$$




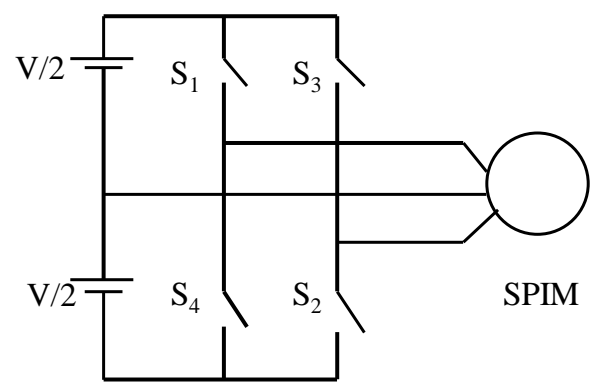

Figure 1. Circuit diagram for speed control of proposed single phase induction motor.

$$
\begin{aligned}
& u_{q s}=i_{q s} r_{q s}+\rho\left(i_{q s} L_{q s}+i_{q r} L_{q m}\right) \\
& i_{d r} r_{r}+\rho \psi_{d r}+\omega_{r} \psi_{q r}=0 \text { and } \psi_{d r}=i_{d r} L_{r}+i_{d s} L_{d m} \\
& i_{q r} r_{r}+\rho \psi_{q r}-\omega_{r} \psi_{d r}=0 \text { and } \psi_{q r}=i_{q r} L_{r}+i_{q s} L_{q m}
\end{aligned}
$$

where, $\omega_{r}$ is the angular speed of the rotor and $\rho$ is the derivation operator. $u_{d s}, u_{q s}, i_{d s}$, $i_{q s}, i_{d r}$ and $i_{q r}$ respectively are stator voltage, stator and rotor currents in the $d$ - $q$ axis. $\psi_{d r}$ and $\psi_{q r}$ are the $d$ - $q$ axis rotor fluxes. $r_{d s}, r_{q s}$ and $r_{r}$ are the stator resistances in the $d-q$ axis and rotor resistance respectively.

$L_{d s}=\left(L_{l d s}+L_{d m}\right), L_{q s}=\left(L_{l q s}+L_{q m}\right)$ and $L_{r}$ are the self inductances of stator in the $d-q$ axis and self inductance of rotor.

$L_{d m}, L_{q m}, L_{l d s}$ and $L_{l q s}$ respectively are the magnetizing inductances and stator leakage inductances in the $d$ - $q$ axis.

$$
T_{e l}=\frac{\mathrm{P}}{2}\left\{L_{q s}\left(i_{q s} i_{d r}\right)-L_{d s}\left(i_{d s} i_{q r}\right)\right\}
$$

The load torque and electromagnetic torque are given by

$$
\left\{J \frac{\mathrm{d} \omega_{r}}{\mathrm{~d} t}+B \omega_{r}\right\}+\left\{\frac{\mathrm{P}}{2} T_{L}\right\}=\left\{\frac{\mathrm{P}}{2} T_{e l}\right\}
$$

The drive attains steady state speed, when $T_{L}=T_{m} \alpha T_{e l}$, where, $P, J, B, T_{e l}, T_{m}$ and $T_{L}$ respectively are the number of poles, moment of inertia, friction, electromagnetic torque, mechanical torque at shaft and the load torque.

Non linear performance is general nature in almost all the systems, design of closed loop control arrangement is always preferred in process industries for superior management of energy and raw materials in order to maximize its manufacture rate [2]. To reduce the deviation between the set point (SP) and the process variable (PV) and to maintain the controlled variable $(\mathrm{CV})$ at the desired value, controllers are introduced. Usually the Proportional (P) controllers are used in the sluggish processes, where as PI controllers are used in the fast process like speed and flow processes. Here, PI controller is designed with $K_{p}=15.411$ and $\tau_{i}=0.13128$ based on Cohen and Coon setting; where, $K_{p}$ is the proportional gain and $\tau_{i}$ is the integral time.

\section{Proposed Neural Network Predictive Controller}

Attaining quality with increasing awareness of environmental responsibility imposes far 
strict demands on control and that can be met by traditional techniques alone. Apart from PI control, a completely different controller design paradigm such as model based control is used, these control algorithms utilizes an explicit plant model to predict future behavior of the plant and creates control signals based on the present error. Implementation of MPC needs linearization because it uses linear models [13]. To highly nonlinear processes such as IM, systems entail servo problems and subjected frequent disturbances a non-linear model is essential. Such circumstances NNPC provides better control since it uses $\mathrm{NM}$ of plant to predict future performance and controller then calculates control input that will optimize the plant performance over a specified future time horizon [22].

\subsection{System Identification}

There are two steps involved in the implementation of NNPC; the first step depends strongly on the identification of system model to train the neural network (NN) to represent the forward dynamics of the plant [22] [23]. The NN plant model uses previous inputs and previous outputs to predict future values of process output [13] [23]. The prediction error between the system output and the NN output is used as the NN training signal. This network is trained using Levenberg-Marquardt (Trainlm) algorithm.

\subsection{Predictive Control}

The second step is controller design, NM predicts the systems response over a specified time horizon and are used by a numerical optimization function to determine control signal to minimizes the performance criterion over the given horizon [22],

$$
J=\sum_{i=N_{1}}^{N_{2}}\left\{y_{r}(t+i)-y_{m}(t+i)\right\}^{2}+\sigma \sum_{i=1}^{N_{\alpha}}\left\{v^{\prime}(t+i-1)-v^{\prime}(t+i-2)\right\}^{2}
$$

where,

$N_{1}$, and $N_{2}$ are define the horizons over which the tracking error,

$N_{u}$ is the control increments to be evaluated,

$V$ 'is the tentative control signal,

$y_{r}$ is the desired response,

$y_{m}$ is the network model response.

The " $\sigma$ " value determines the contribution that the sum of the squares of the control increments has on the performance index.

\section{Simulation Results}

To validate the proposed NNPC scheme, a simulation using MATLAB has been created for a SPIM with $0.25 \mathrm{hp}, 220 \mathrm{~V}, 50 \mathrm{~Hz}, 4$ pole motor for servo and regulatory problems, the parameters are given in Table 1 . Since the machine is quarter $\mathrm{hp}$, its full load torque is $0.65 \mathrm{~N}-\mathrm{m}$; it is assumed that it may require negligible torque to compensate the frictional loss and is if employed with contact less sensors for speed feedback. 
Table 1. Parameters of proposed SPIM.

\begin{tabular}{cc}
\hline Motor Parameters & Numerical Value \\
\hline $\mathrm{R}_{\mathrm{sm}}$ & $2.02 \Omega$ \\
$\mathrm{R}_{\mathrm{rm}}^{\prime}$ & $4.12 \Omega$ \\
$\mathrm{L}_{\mathrm{sm}}$ & $8.88 \mathrm{e}^{-3} \mathrm{H}$ \\
$\mathrm{L}_{\mathrm{rm}}^{\prime}$ & $6.72 \mathrm{e}^{-3} \mathrm{H}$ \\
$\mathrm{R}_{\mathrm{sa}}$ & $7.14 \Omega ;$ \\
$\mathrm{L}_{\mathrm{sa}}$ & $10.2 \mathrm{e}^{-3} \mathrm{H}$ \\
$\mathrm{L}_{\mathrm{m}}$ & $0.21264 \mathrm{H}$ \\
$\mathrm{J}$ & $0.0416 \mathrm{~kg} \cdot \mathrm{m}^{2}$ \\
Turns Ratio & 1.25 \\
\hline
\end{tabular}

\subsection{Servo Response}

The open loop response of the proposed SPIM at no load is shown in Figure 2; in which the linear region lies between $450 \mathrm{rpm}$ and $1430 \mathrm{rpm}$. But running the machine at too low speed with full load is not possible without sacrificing its speed or torque because of its inverse characteristic nature $\left(N \alpha \frac{1}{T}\right)$. Here, at full load on considering $1300 \mathrm{rpm}$ as mid value in the linear region, from which it is possible to amend \pm 140 rpm (1440 rpm and $1160 \mathrm{rpm}$ ) being considered as future change in set point. Unlike PI controllers, the NNPC can able to operate well in the non linear regions up to some extent, here the proposed controller works well for the speed ranges between $1120 \mathrm{rpm}$ and $1440 \mathrm{rpm}$ at full load.

A well designed controller must follow the set point changes for future inputs, this is referred as servo problems in control system terminology. If the controller does not operate satisfactorily for set point changes then there is no use of such controllers, a simple ON-OFF controller can perform the same work. Further the cost involved is very high. So, it is required to simulate and to verify the servo response of the process with the proposed controller. If the proposed controller performs satisfactorily then only the designed controller is implemented in real time process otherwise the design is to be modified. The servo response of conventional PI controller and NNPC are shown in Figure 3. From the servo response it is proven that designed controllers provide satisfied response for $1300 \mathrm{rpm}, 1440 \mathrm{rpm}$ and $1120 \mathrm{rpm}$ at full load torque of $0.65 \mathrm{~N}-\mathrm{m}$.

\subsection{Steady State Speed Response}

The transient part is not much important for industrial drives because it will quickly reach steady state, in most cases the load is linked after the drive attains steady speed. Further the motor operates in the stable region when the motor torque is equals to load torque. Otherwise the motor goes to unstable region results drastic speed changes and failure of operation. So it is requisite to analyze the steady state behavior of the drive, the steady state responses for set speeds of $1300 \mathrm{rpm}, 1440 \mathrm{rpm}$ and $1120 \mathrm{rpm}$ respectively at full load are shown in Figures 4(a)-(c), In all the cases it is seen that the 


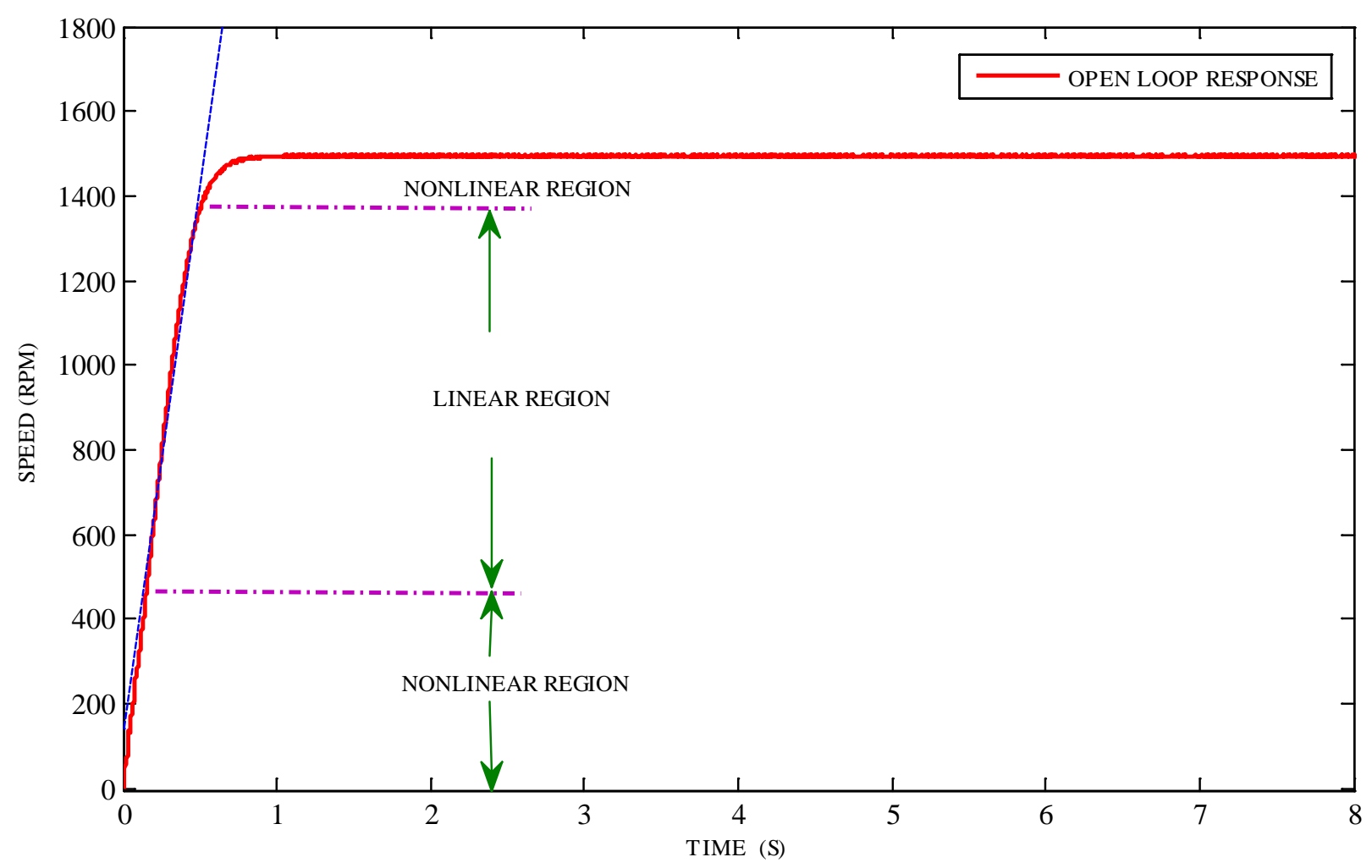

Figure 2. Open loop response of the proposed single phase induction motor at no load.

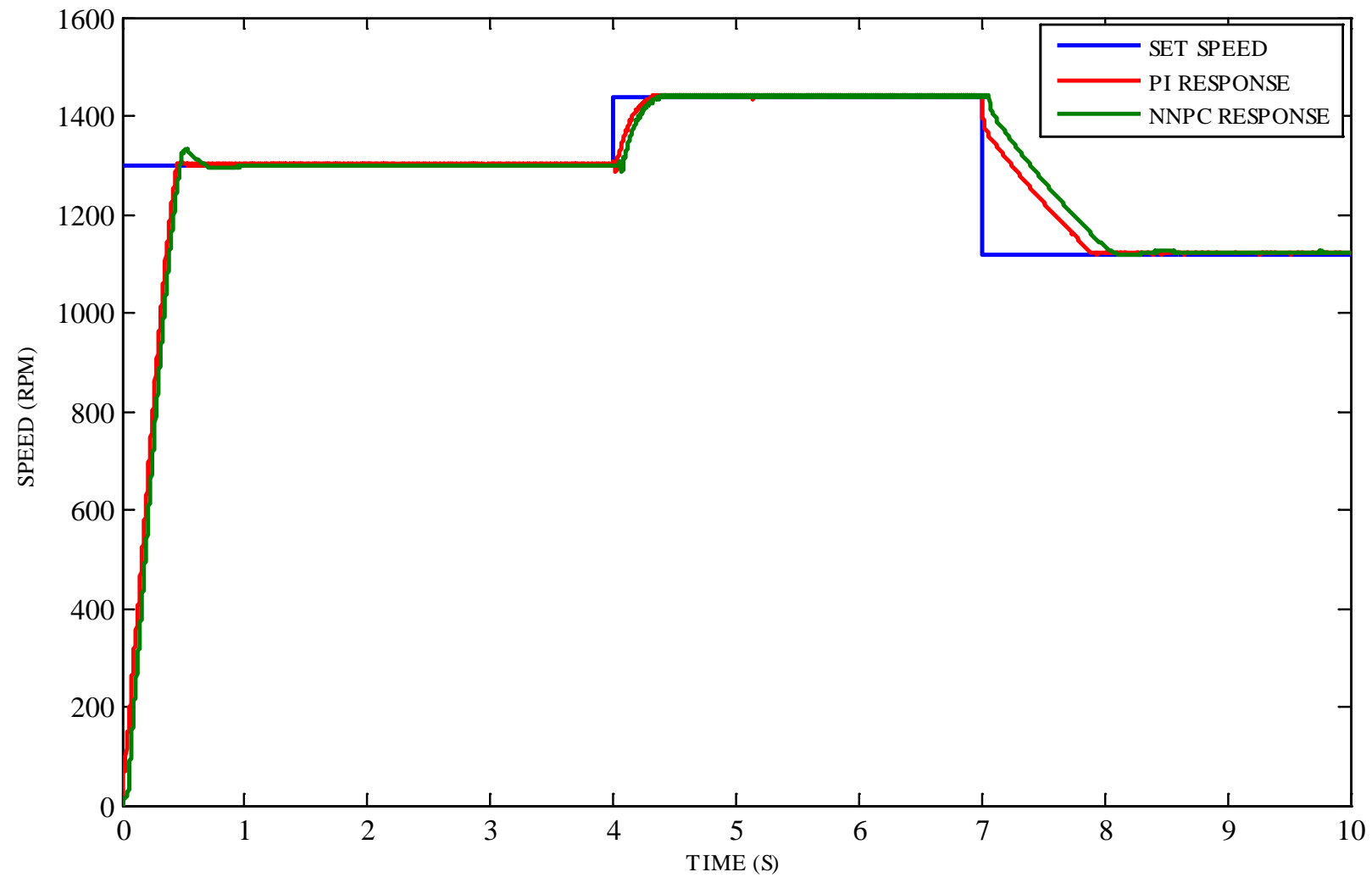

Figure 3. Servo response of SPIM with NNPC and PI controller. 


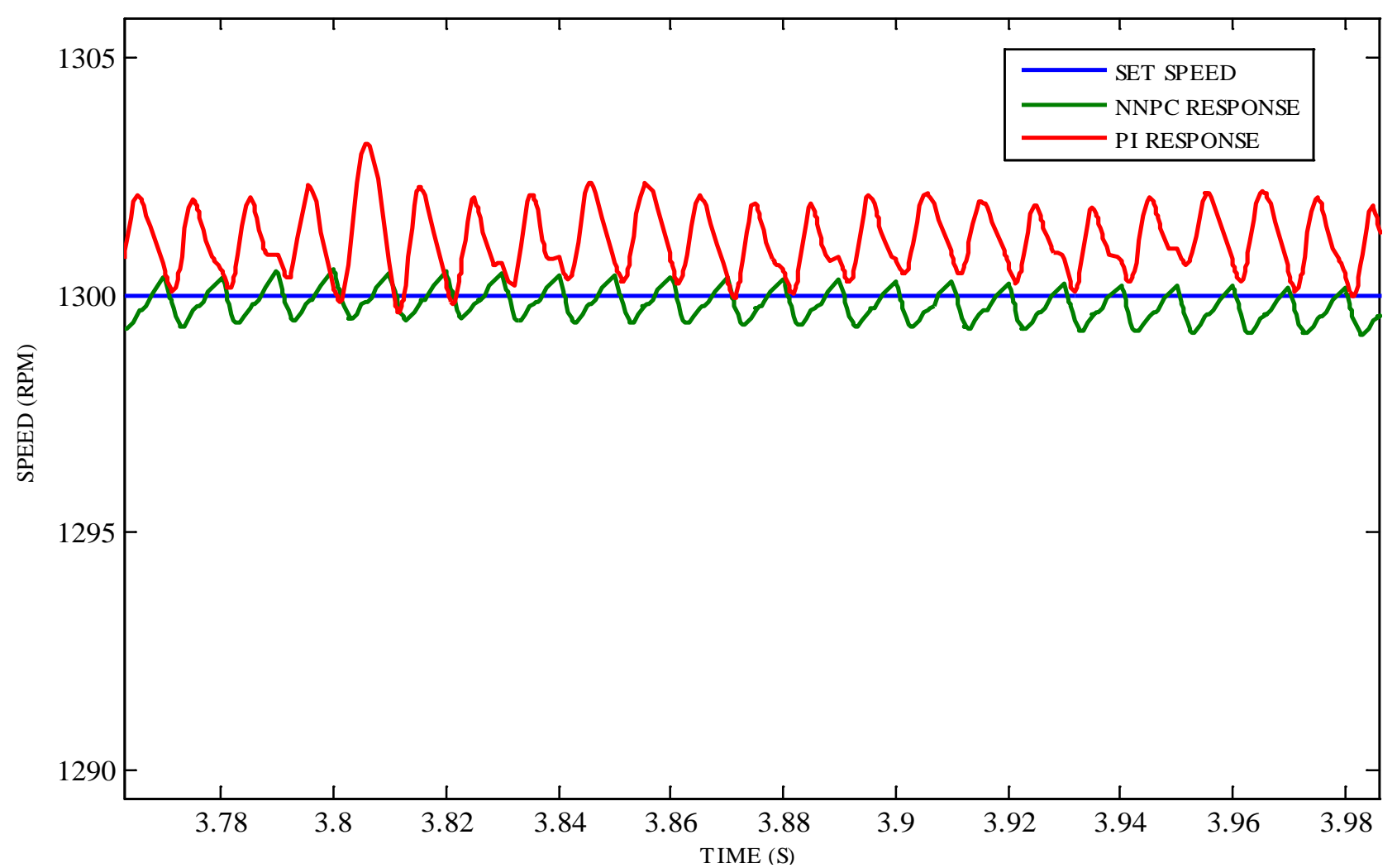

(a)

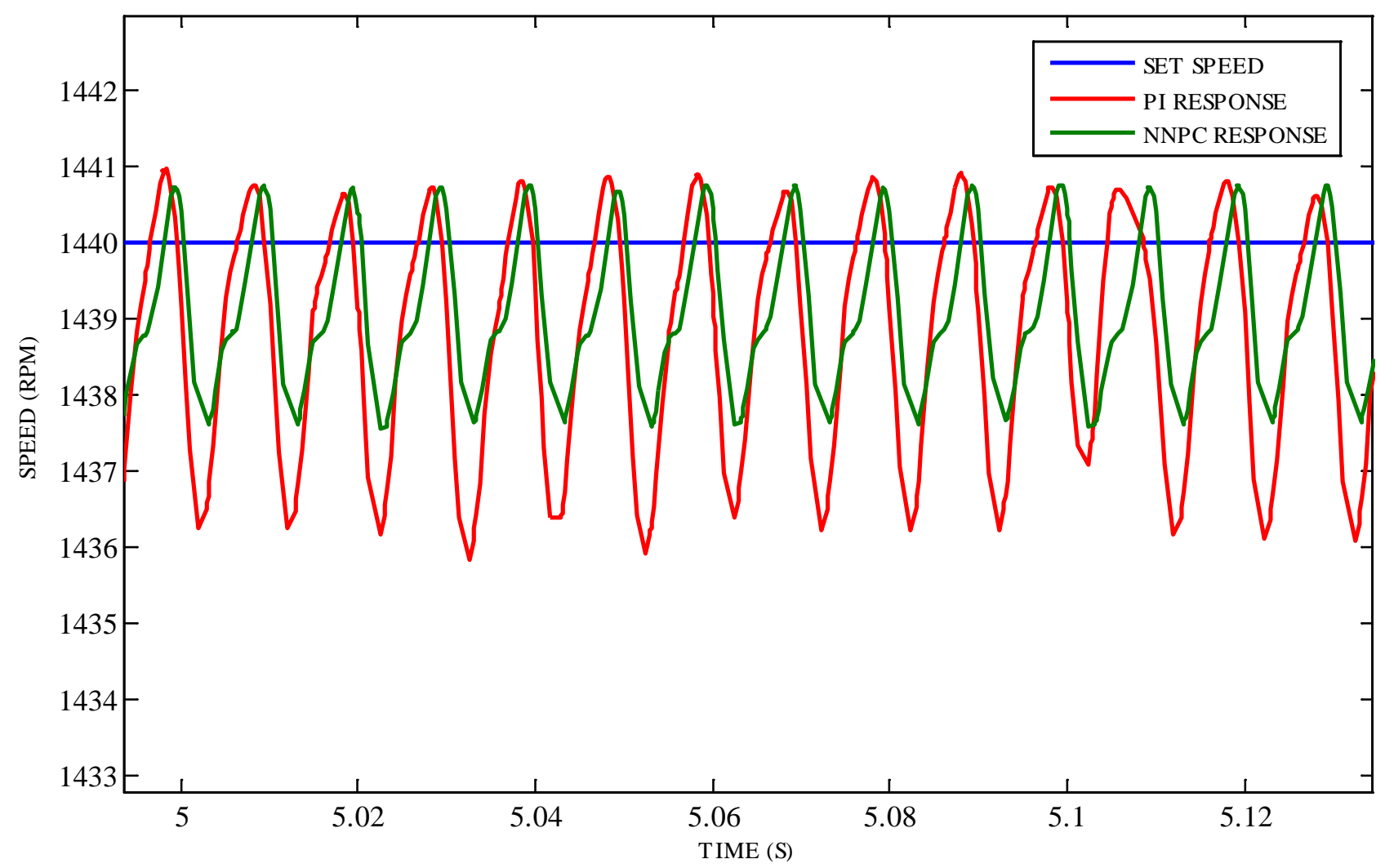

(b) 


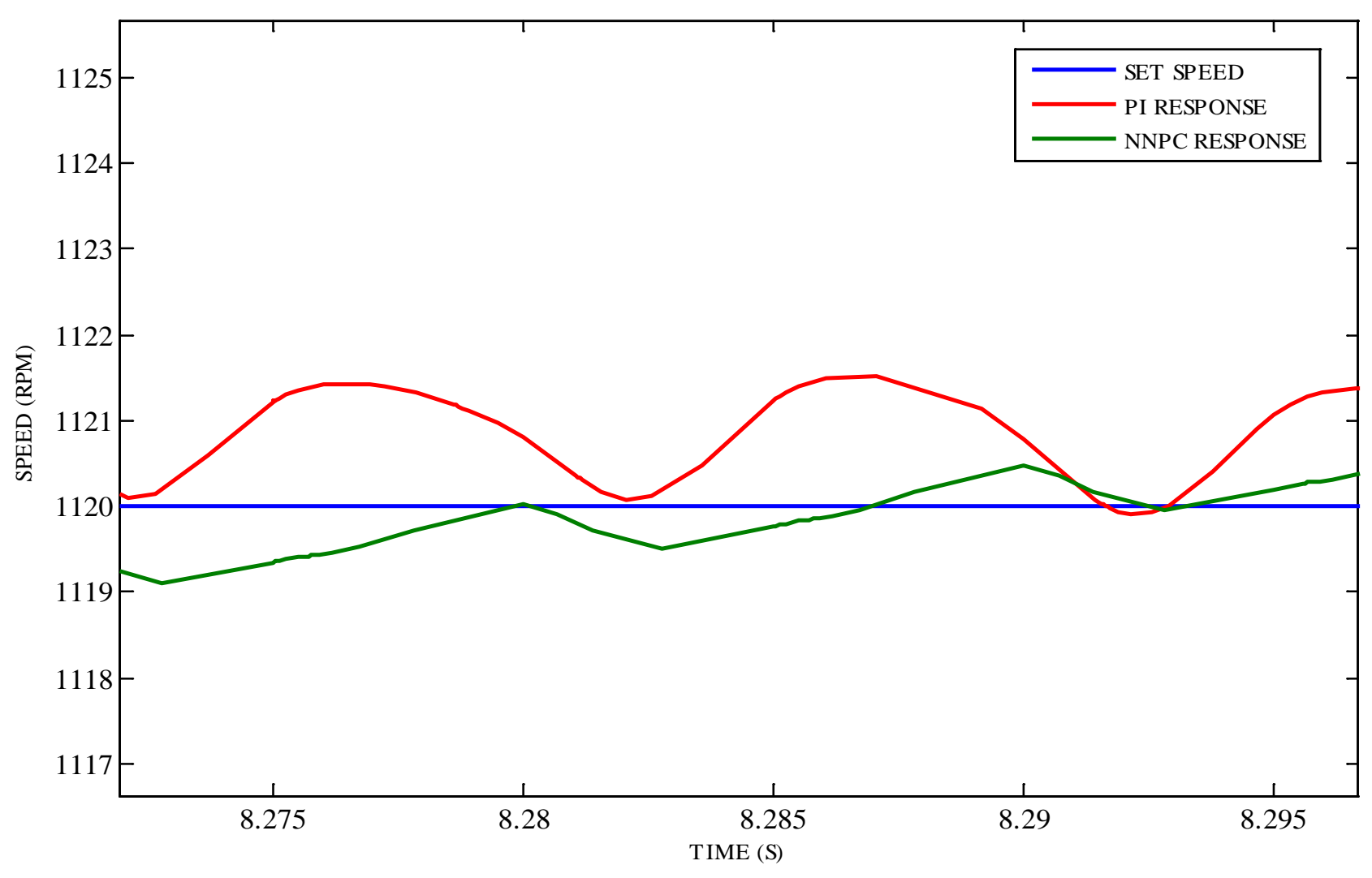

(c)

Figure 4. (a) Steady state response at full load (at $1300 \mathrm{rpm}$ ); (b) Steady state response at full load (at $1440 \mathrm{rpm}$ ); (c) Steady state response at full load (at $1120 \mathrm{rpm}$ ).

NNPC response is closer to the set speed of the motor compared to PI controller response, the steady state response for different set speed proves that the proposed controller provides better performance than the conventional PI controller.

\subsection{Regulatory Response}

Industrial processes are subjected to recurrent supply voltage and load variations, these are referred as load changes in the control system terminology. Consequences frequent variations in the drives speed, which affect both drives performance and product quality. From this it is obligatory to check whether the designed controller can suppress the load disturbances effectively or not and we call it has regulatory problems. Normally the controllers are checked with $2 \%$ to $5 \%$ of load disturbances, the maximum allowable load changes are up to $5 \%$ of the final value. Regulatory responses for $5 \%$ rising and decreasing load torques (at 2 seconds) are shown respectively in Figure 5(a) and Figure 5(b). It is shown that the proposed NNPC effectively discards the load torque variations at a given set speed.

\section{Electromagnetic Torque}

The electromagnetic torque corresponding to the afore said set speeds given in servo 


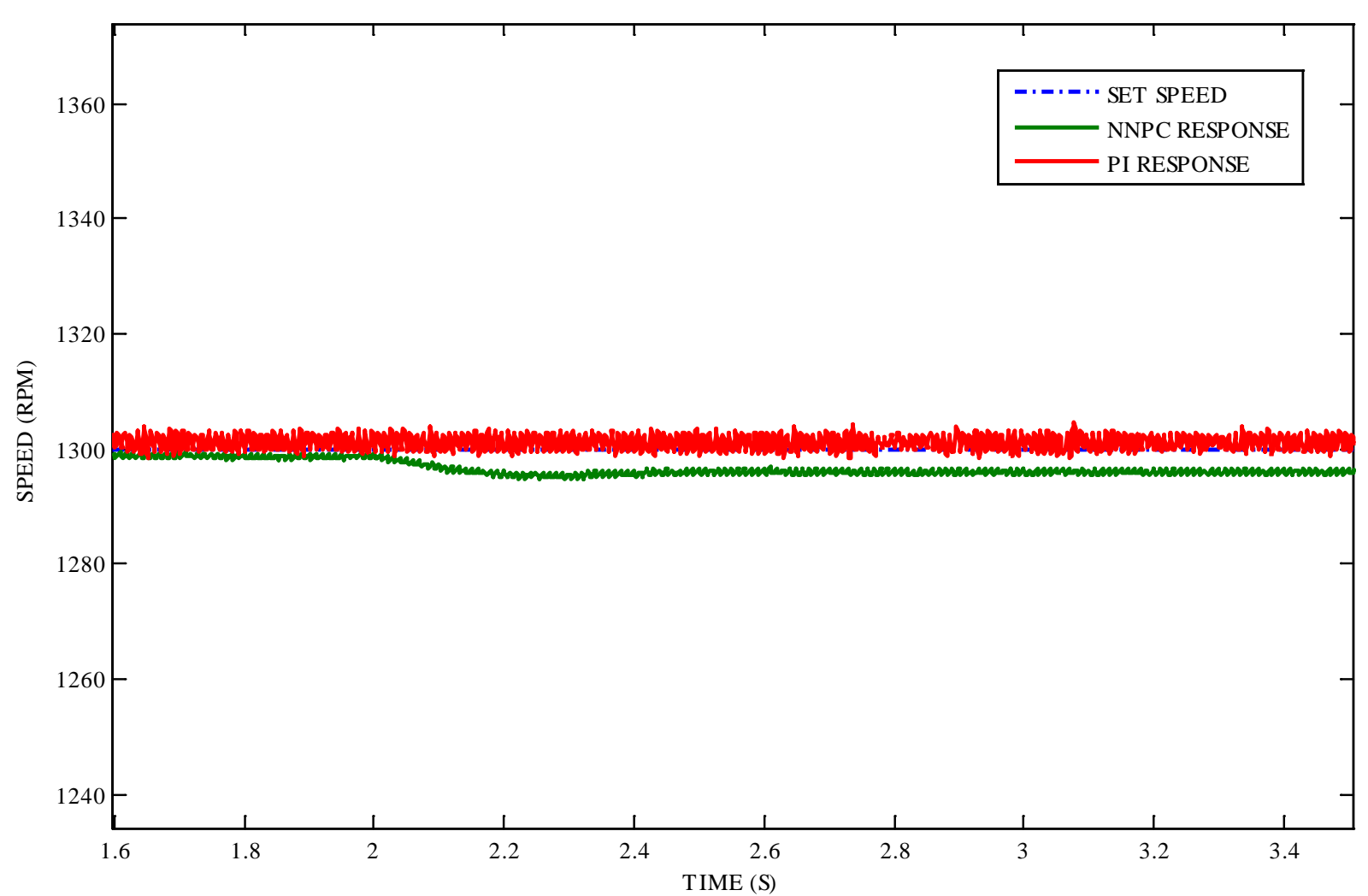

(a)

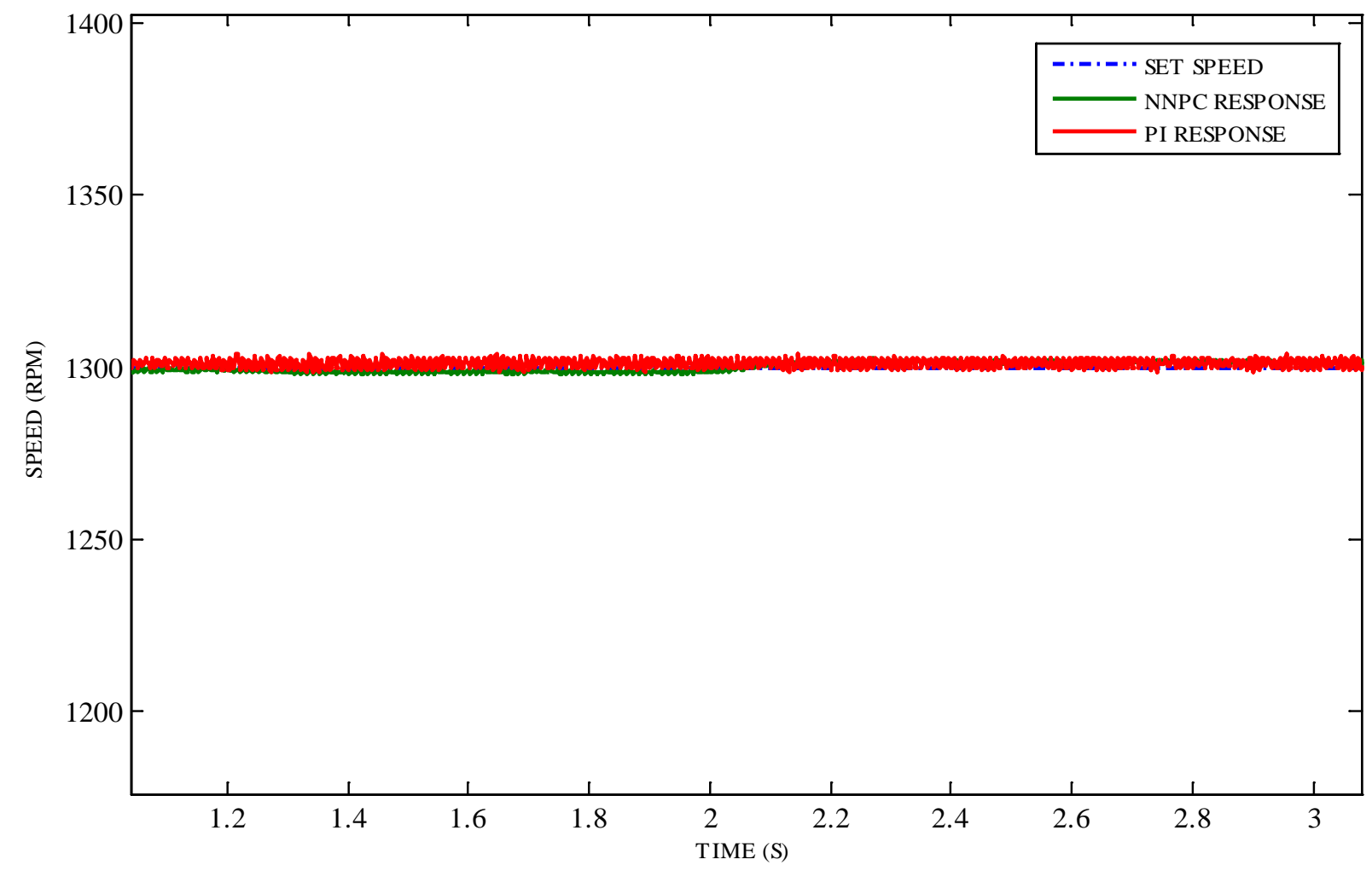

(b)

Figure 5. (a) Regulatory response for 5\% load addition; (b) Regulatory response for 5\% load reduction. 
problem are shown in Figure 6, from this it have been evidently proven that, the NNPC had low torque ripples than the PI controllers.

\section{Steady State Torque Response}

The steady state torque at $1300 \mathrm{rpm}, 1440 \mathrm{rpm}$ and $1120 \mathrm{rpm}$ of set speeds are respectively shown in Figures 7(a)-(c).

There is ripple in speed, from Figures 4(a)-(c) it is seen that the proposed NNPC have low speed ripples than PI controller. From Figures 7(a)-(c) it is known that the proposed NNPC exhibit low torque ripples than the PI controller. From Table 2 it is revealed that the torque and speed ripples are less with proposed NNPC compared to PI controller.

\section{Conclusion}

In this research, neural network predictive controller has been designed and it uses neural model of the nonlinear plant for identification. The NM uses previous inputs and previous plant outputs for prediction of future values of the plant response. Based on the predicted plant output of the NM, the future error is estimated and the controller output is modified according to this predicted future error. Due to this action the error is suppressed prior to its actual appearance in the process that is why its performance is superior to the other controllers. This network has been trained offline in

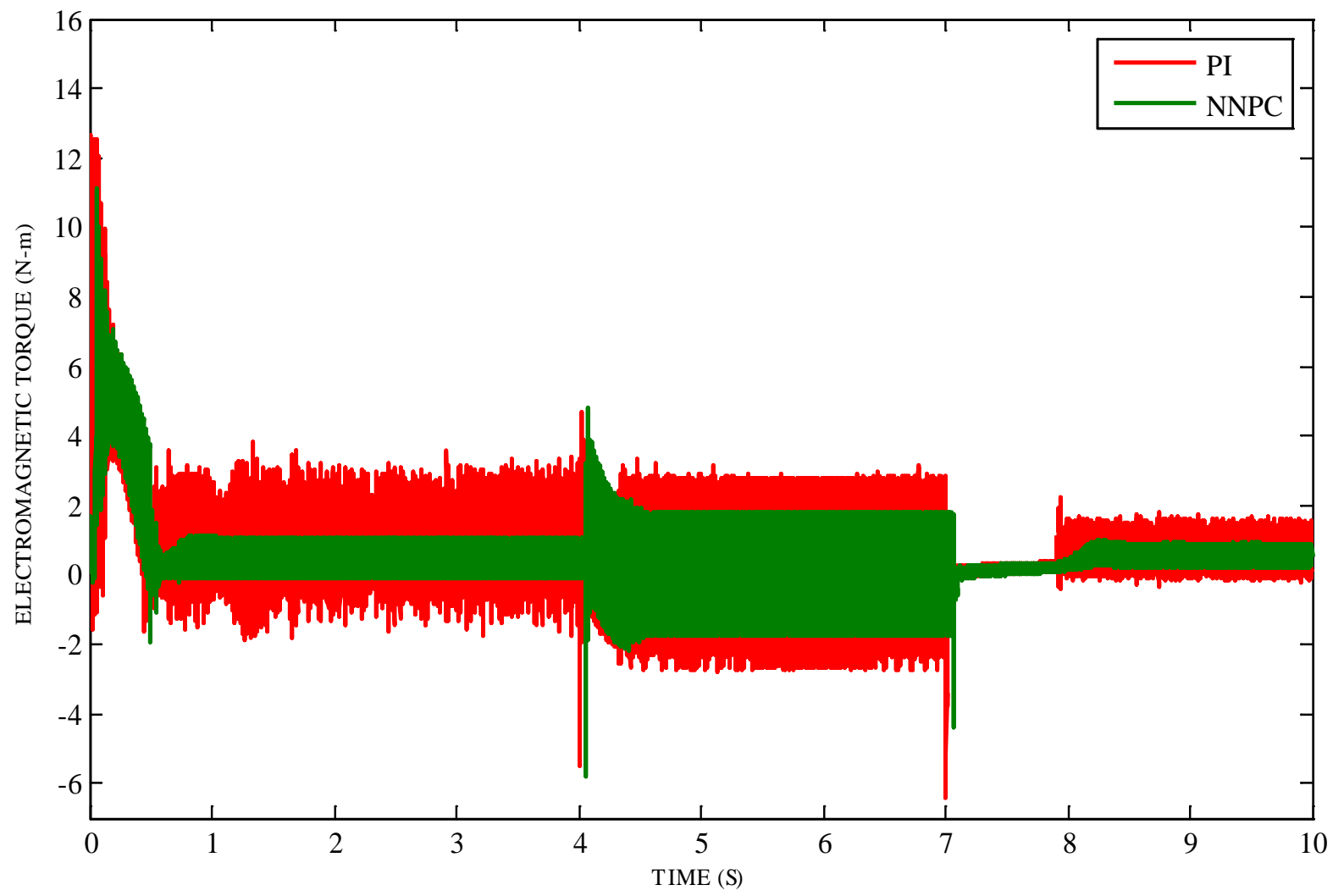

Figure 6. Electromagnetic torque. 


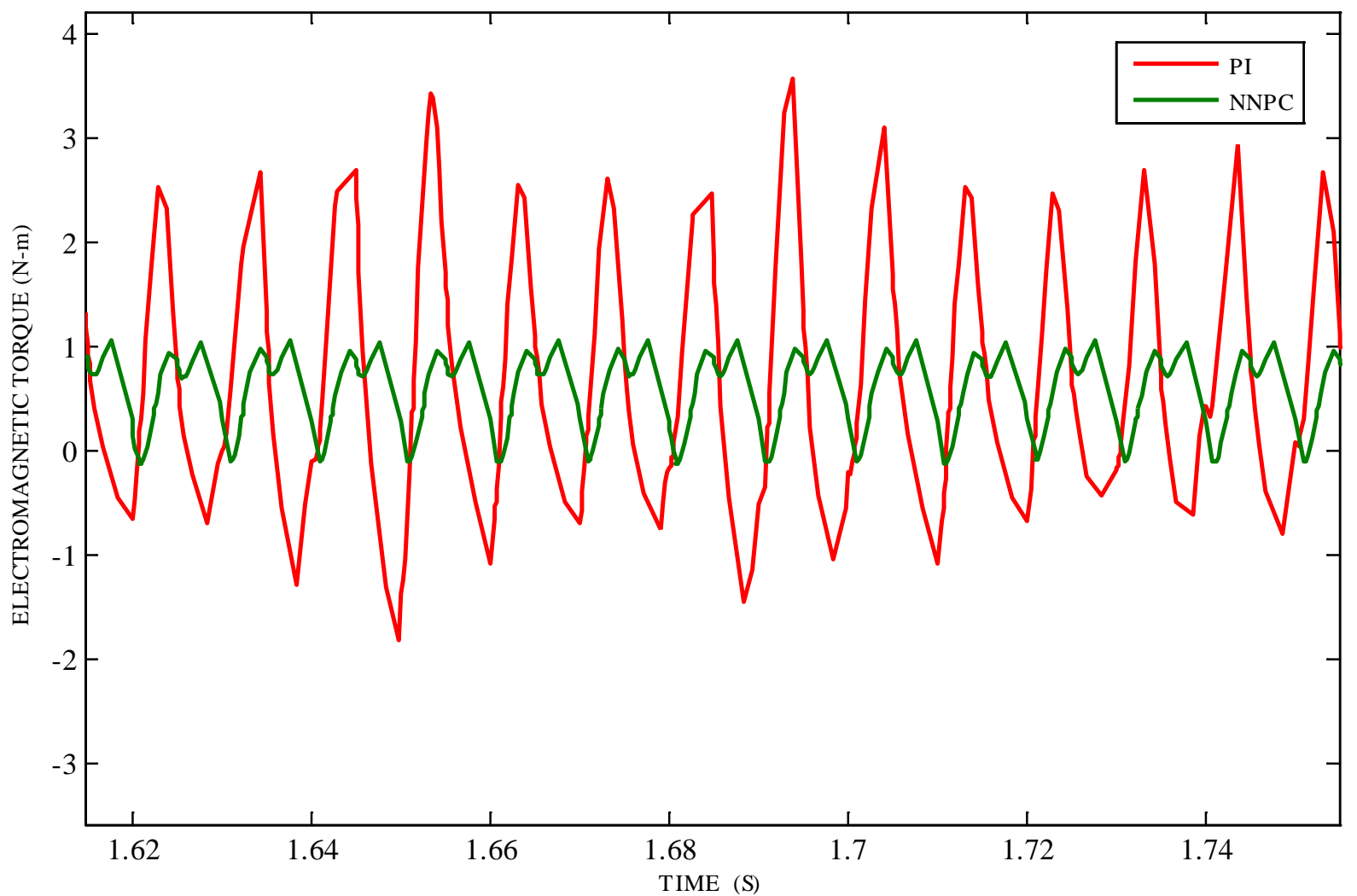

(a)

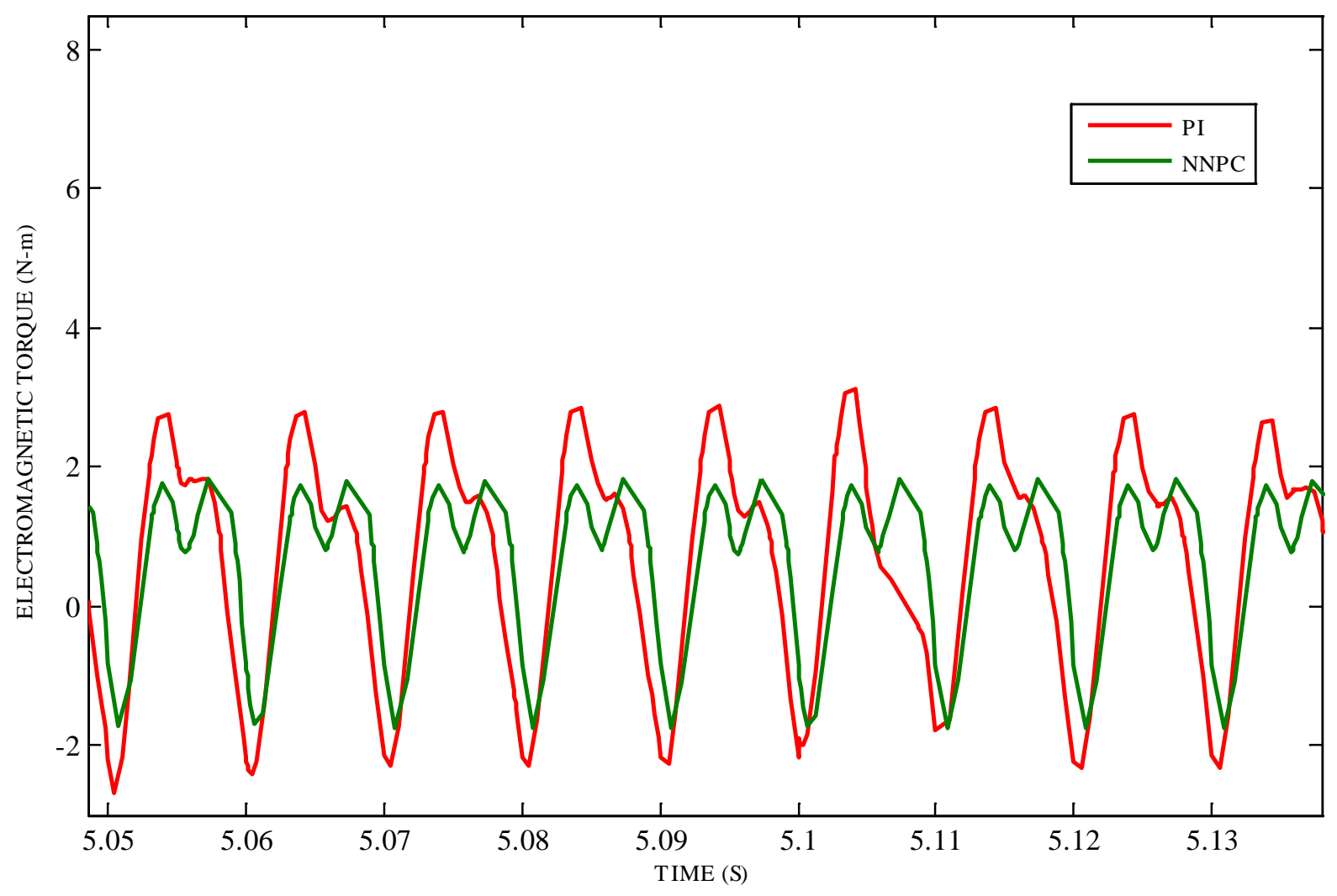

(b) 


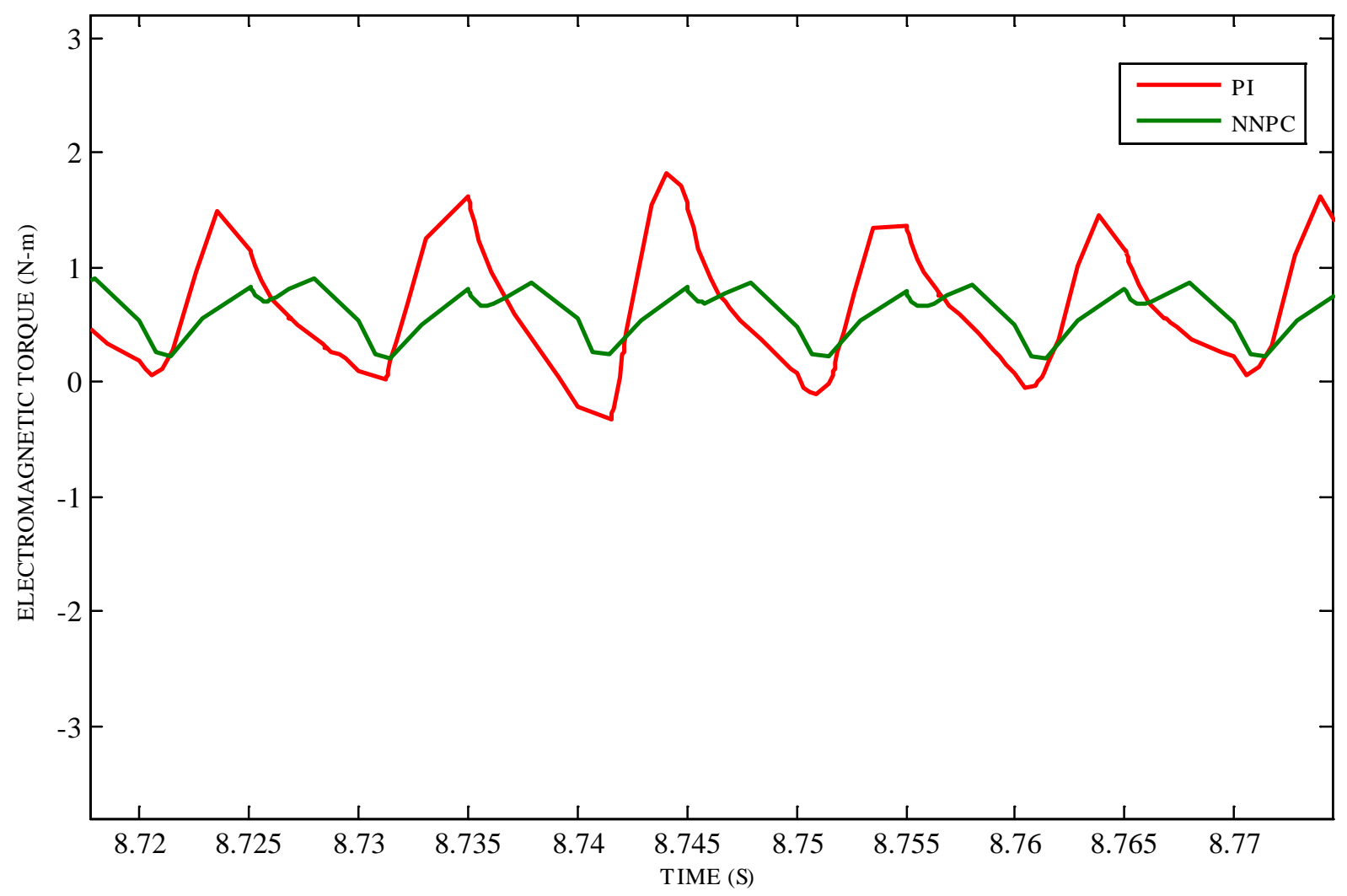

(c)

Figure 7. (a) Steady state torque at $1300 \mathrm{rpm}$; (b) Steady state torque at $1440 \mathrm{rpm}$; (c) Steady state torque at $1120 \mathrm{rpm}$.

Table 2. Speed ripples in $\%$ of final speed and torque average.

\begin{tabular}{ccccc}
\hline \multirow{2}{*}{ Set Speed $(\mathrm{rpm})$} & \multicolumn{2}{c}{ \% Speed Ripples } & \multicolumn{2}{c}{ Torque Average } \\
\cline { 2 - 5 } & NNPC & PI Control & NNPC & PI Control \\
\hline 1120 & 0.026 & 0.133 & 0.349 & 0.7485 \\
1300 & 0.1 & 0.273 & 0.481 & 1.2575 \\
1440 & 0.211 & 0.35 & 0.04 & 0.15 \\
\hline
\end{tabular}

batch mode, using the data collected from the plant which is to be controlled. The designed controller calculates the control input that will optimize the plant performance over the specified future time horizon.

In this work, speed control of SPIM using PI controller and NNPC control technique has been analyzed using a MATLAB environment with a computer of $2.27 \mathrm{GHz}$ core i3 processor with $2.00 \mathrm{~GB}$ RAM memory and compared. In the servo and regulatory performances, both techniques provide a fast speed dynamic performance, but in steady state the NNPC has lower speed ripples and is very close to the set value compared to conventional controller. Further, the electric torque has lower ripple in the NNPC compared to PI controller. From the simulation results, it is obtained that NNPC provides a comparative performance than the conventional controller. 


\section{References}

[1] Alsofyani, I.M. and Idris, N.R.N. (2016) Simple Flux Regulation for Improving State Estimation at Very Low and Zero Speed of a Speed Sensorless Direct Torque Control of an Induction Motor. IEEE Transactions on Power Electronics, 31, 3027-3035.

http://dx.doi.org/10.1109/TPEL.2015.2447731

[2] Latha, K., Rajinikanth, V. and Surekha, P.M. (2013) PSO-Based PID Controller Design for a Class of Stable and Unstable Systems. Hindawi Publishing Corporation, Cairo, 1-11. http://dx.doi.org/10.1155/2013/543607

[3] Sakthivel, V.P., Bhuvaneswari, R. and Subramanian, S. (2010) Economic Design of ThreePhase Induction Motor by Particle Swarm Optimization. Journal of Electromagnetic Analysis and Applications, 2, 301-310. http://dx.doi.org/10.4236/jemaa.2010.25039

[4] Song, W.S., Ma, J.P., Zhou, L. and Feng, X.Y. (2016) Deadbeat Predictive Power Control of Single-Phase Three-Level Neutral-Point-Clamped Converters Using Space-Vector Modulation for Electric Railway Traction. IEEE Transactions on Power Electronics, 31, 721-732. http://dx.doi.org/10.1109/TPEL.2015.2400924

[5] Rajinikanth, V. and Latha, K. (2012) Set Point Weighted PID Controller Tuning for Unstable System Using Heuristic Algorithm. Archives of Control Sciences, 22, 481-505. http://dx.doi.org/10.2478/v10170-011-0037-8

[6] Naga Sujatha, K. and Vaisakh, K. (2010) Implementation of Adaptive Neuro Fuzzy Inference System in Speed Control of Induction Motor Drives. Journal of Intelligent Learning Systems and Applications, 2, 110-118. http://dx.doi.org/10.4236/jilsa.2010.22014

[7] Fu, X.G. and Li, S.H. (2015) A Novel Neural Network Vector Control Technique for Induction Motor Drive. IEEE Transactions on Energy Conversion, 30, 1428-1437. http://dx.doi.org/10.1109/TEC.2015.2436914

[8] Riveros, J.A., Barrero, F., Levi, E., Durán, M.J., Toral, S. and Jones, M. (2013) VariableSpeed Five-Phase Induction Motor Drive Based on Predictive Torque Control. IEEE Transactions on Industrial Electronics, 60, 2957-2968.

http://dx.doi.org/10.1109/TIE.2012.2198034

[9] Aly, A.A. (2011) PID Parameters Optimization Using Genetic Algorithm Technique for Electro hydraulic Servo Control System. Intelligent Control and Automation, 2, 69-76. http://dx.doi.org/10.4236/ica.2011.22008

[10] Rajinikanth, V. and Latha, K. (2012) Tuning and Retuning of PID Controller for Unstable Systems Using Evolutionary Algorithm. ISRN Chemical Engineering, 2012, Article ID: 693545. http://dx.doi.org/10.5402/2012/693545

[11] Li, J., Ren, H.-P. and Zhong, Y.-R. (2015) Robust Speed Control of Induction Motor Drives Using First-Order Auto-Disturbance Rejection Controllers. IEEE Transactions on Industry Applications, 51, 712-720. http://dx.doi.org/10.1109/TIA.2014.2330062

[12] Asseu, O., Kouacou, M.A., Ori, T.R., Yéo, Z., Koffi, M. and Lin-Shi, X. (2010) Nonlinear Control of an Induction Motor Using a Reduced-Order Extended Sliding Mode Observer for Rotor Flux and Speed Sensorless Estimation. Engineering, 2, 813-819. http://dx.doi.org/10.4236/eng.2010.210104

[13] Zhang, Y.C. and Yang, H.T. (2014) Model Predictive Torque Control of Induction Motor Drives with Optimal Duty Cycle Control. IEEE Transactions on Power Electronics, 29, 6593-6603. http://dx.doi.org/10.1109/TPEL.2014.2302838

[14] Fuentes, E., Kalise, D., Rodríguez, J. and Kennel, R.M. (2014) Cascade-Free Predictive Speed Control for Electrical Drives. IEEE Transactions on Industrial Electronics, 61, 2176-2184. http://dx.doi.org/10.1109/TIE.2013.2272280 
[15] Vasičkaninová, A. and Bakošová, M. (2009) Neural Network Predictive Control of a Chemical Reactor. Acta Chimica Slovaca, 2, 21-36.

[16] Preindl, M. and Bolognan, S. (2013) Model Predictive Direct Speed Control with Finite Control Set of PMSM Drive Systems. IEEE Transactions on Power Electronics, 28, 1007 1015. http://dx.doi.org/10.1109/TPEL.2012.2204277

[17] Jang, D.-H. (2013) Problems Incurred in a Vector-Controlled Single-Phase Induction Motor and a Proposal for a Vector-Controlled Two-Phase Induction Motor as a Replacement. IEEE Transactions on Power Electronics, 28, 526-536. http://dx.doi.org/10.1109/TPEL.2012.2199772

[18] Ziaeinejad, S., Sangsefidi, Y., Nabi, H.P. and Shoulaie, A. (2013) Direct Torque Control of Two-Phase Induction and Synchronous Motors. IEEE Transactions on Power Electronics, 28, 4041-4050. http://dx.doi.org/10.1109/TPEL.2012.2230409

[19] Zhang, Y., Zhu, J., Zhao, Z., Xu, W. and Dorrell, D.G. (2012) An Improved Direct Torque Control for Three-Level Inverter-Fed Induction Motor Sensorless Drive. IEEE Transactions on Power Electronics, 27, 1502-1513. http://dx.doi.org/10.1109/TPEL.2010.2043543

[20] El Badsi, B., Bouzidi, B. and Masmoudi, A. (2013) DTC Scheme for a Four-Switch Inverter-Fed Induction Motor Emulating the Six-Switch Inverter Operation. IEEE Transactions on Power Electronics, 28, 3528-3538. http://dx.doi.org/10.1109/TPEL.2012.2225449

[21] Gule, N. and Maarten Kamper, J. (2012) Multiphase Cage-Rotor Induction-Machine Drive with Direct Implementation of Brush DC Operation. IEEE Transactions on Industry Applications, 48, 2014-2021. http://dx.doi.org/10.1109/TIA.2012.2226195

[22] Demuth, H. and Beale, M. (2003) Neural Network Toolbox for Use with MATLAB. User Guide, the MATH WORKS Inc.

[23] Marcic, T., Štumberger, B. and Štumberger, G. (2012) Comparison of Induction Motor and Line-Start IPM Synchronous Motor Performance in a Variable-Speed Drive. IEEE Transactions on Industry Applications, 48, 2341-2352. http://dx.doi.org/10.1109/TIA.2012.2227095

Submit or recommend next manuscript to SCIRP and we will provide best service for you:

Accepting pre-submission inquiries through Email, Facebook, LinkedIn, Twitter, etc.

A wide selection of journals (inclusive of 9 subjects, more than 200 journals)

Providing 24-hour high-quality service

User-friendly online submission system

Fair and swift peer-review system

Efficient typesetting and proofreading procedure

Display of the result of downloads and visits, as well as the number of cited articles

Maximum dissemination of your research work

Submit your manuscript at: http://papersubmission.scirp.org/ 